Magna Scientia Advanced Research and Reviews

eISSN: 2582-9394

Cross Ref DOI: $10.30574 / \mathrm{msarr}$

Journal homepage: https://magnascientiapub.com/journals/msarr/

(REVIEW ARTICLE)

\title{
Prevalence of Diarrhoeal Diseases among Under-Five Paediatric Patients in a Tertiary Health Care Facility, South Eastern Nigeria: A 5-Year Review
}

Udemezue Ebube Ezeife ${ }^{1}$, Onyeka Chukwudalu Ekwebene ${ }^{2,}{ }^{*}$, Franklyne Chineye Akubukor 1, Chioma Favour Ekwebene ${ }^{3}$, Somtochukwu Daniel Abazu ${ }^{4}$ and Chidera Gabriel Edeh ${ }^{1}$

${ }^{1}$ Faculty of Medicine, Nnamdi Azikiwe University, Nnewi Campus, Anambra State, Nigeria.

${ }^{2}$ Nnamdi Azikiwe University Teaching Hospital, Nnewi, Anambra State, Nigeria.

${ }^{3}$ College of Nursing, Diocesean Hospital, Amichi, Anambra State, Nigeria.

${ }^{4}$ Kuro Specialist Hospital, Yenagoa, Bayelsa State, Nigeria.

Magna Scientia Advanced Research and Reviews, 2021, 03(01), 071-078

Publication history: Received on 21 September 2021; revised on 24 October 2021; accepted on 26 October 2021

Article DOI: https://doi.org/10.30574/msarr.2021.3.1.0072

\begin{abstract}
Background: Diarrhoeal disease remains a major cause of morbidity and mortality in children, especially in developing countries. Although Nigeria has already achieved remarkable progress in reducing under-five mortality in the last decades, studies done in different parts of Nigeria had shown that diarrhoea is still a major public health problem.
\end{abstract}

Objectives: This study aimed at determining the prevalence of diarrhoea in under-five children who presented to Nnamdi Azikiwe University Teaching Hospital Neni through the period of January 2016 - December 2020, a 5-year review. It is also aimed at noting the influence of other socio demographic factors such as age, sex and seasonal variation on the occurrence of diarrhoeal diseases.

Methods: A retrospective study design was used as patients' records were obtained from the medical records for the said duration of study and a pro forma was used in extracting needed information.

Results: A total of 128 cases of diarrhoeal disease were recorded out of the 897 under-five aged children that visited the hospital at the said period of study. Thus with a prevalence of $14.27 \%$. Higher number of cases were recorded in the dry season $96(75.0 \%)$ than the wet season; $32(25.0 \%)$ cases. More males were affected; $78(60.1 \%)$ than females;50 (39.1\%). Children aged 0-11 months were affected more; 62 (48.4\%) followed by those within the age bracket of 12-23 months $32(25.0 \%)$ with those within the ages $48-59$ months having the least number of cases; 8 (6.3\%).

Conclusions: From the study it was concluded that diarrhoea occurs more in the dry season in this region than in the wet season. It was also concluded that the general risk of diarrhoeal disease decreases with increasing age in children and toddlers are the most at risk group of suffering the disease.

Keywords: Diarrhoeal disease; Under-five; Paediatric patients; Prevalence

\section{Introduction}

Diarrhoeal disease remains a major cause of morbidity and mortality in children, especially in the less developed countries of the world. It is estimated that in a year approximately one billion episodes of diarrhoea occur among children under-five years of age in Africa, Asia and Latin America, with more than 4 million deaths. Studies in Nigeria

\footnotetext{
${ }^{*}$ Corresponding author: Onyeka Chukwudalu Ekwebene

Nnamdi Azikiwe University Teaching Hospital, Nnewi, Anambra State, Nigeria.
}

Copyright $(2021$ Author(s) retain the copyright of this article. This article is published under the terms of the Creative Commons Attribution Liscense 4.0 . 
have also shown diarrhoea as one of the most common cause of death among hospitalized children under-fiveyears of age [1].

According to the World Health Organization (WHO), diarrhoea is defined as the passage of three or more loose or liquid stools per day due to abnormally high fluid content of stool. Or an abnormal increase in daily stool fluidity, frequency, and volume from what is considered normal for an individual [2]. Diarrhoeal diseases have been a major public health concern of low-income countries leading to high morbidity and mortality among under-five children [3]. Diarrhoeal diseases account for 1 in 9 or $9 \%$ of child deaths worldwide, making diarrhoea the second leading cause of death among children under the age of five [4,5]. In Africa and South Asia more than four-fifths of all under-five deaths $(82 \%)$ are caused by diarrhoeal diseases [6].

Although Nigeria has already achieved remarkable progress in reducing under-five mortality in the last decades, diarrhoeal diseases are still a common problem. Studies done in different parts of Nigeria had shown that diarrhoea is still a major public health problem. Though the factors that contribute to the occurrence of diarrhoeal diseases among children under the age of 5 years is complex, the relative contribution of socioeconomic, environmental, and behavioral factors should not be underestimated [1].

So this study is aimed to access the prevalence and possibly, the associated risk factors of diarrhoeal diseases among children under the age 5 years. With this information at hand, appropriate interventional strategies could be designed to avert the menaces of diarrhoeal disease. It could also provide information for program providers and managers to address the gap. Furthermore, the findings obtained from this study will provide baseline information for further researchers.

\subsection{Research questions}

- What is the prevalence of diarrhoea in under-five children who accessed care at NAUTH Neni between January 2016 through December 2020?

- What is the pattern/seasonal variation in occurrence of diarrhoea in children aged less than five years who accessed care at NAUTH Neni between January 2016 through December 2020?

- Is the occurrence of diarrhoea significantly more common in a particular sex among under-five children who accessed care at NAUTH Neni between January 2016 through December 2020?

\section{Methodology}

\subsection{Study location}

This study was conducted at Nnamdi Azikiwe University Teaching Hospital (NAUTH) Neni, Anambra State, Nigeria. It is an outstation of NAUTH Nnewi, primarily for the department of community medicine. Neni is an Igbo speaking rural community in the southeastern Nigeria and one of the nine towns that make up Anaocha Local Government Area of Anambra State. Anaocha LGA has a total population of 248,215 (with a 0-9 years' population of 67,945 ) based on the 2006 census and a projected population of 376,100 for 2016 [16]. Neni's geographical coordinates are 6" $09^{\prime} 00$ North, 7" 02 ' 00 East. Members of the community are majorly Christians and their major occupations are farming, trading (food stuff) and civil service. Neni, a community in Nigeria is blessed with 2 climate seasons as is common in most West African countries; the wet and the dry/harmattan seasons. The wet seasons spans averagely from the month of April to the month of October while the dry season covers mainly from the month of November to the month of march. The headquarters of the Anaocha Local Government Area is also located at Neni.

\subsection{Study design}

This was a retrospective study on the prevalence of diarrhea in under-five patients.

\subsection{Study population}

The study included paediatric patients aged less than five years, who visited NAUTH Neni for treatment of diarrhoea from January 2016 through December 2020 (a 5-year study).

\subsubsection{Inclusion criteria}

Inclusion criteria for the study; 
- Children aged less than 5 years who were diagnosed of diarrhoeal disease both exclusively and inclusively with other diseases

- Children aged less than five who accessed care on account of diarrhoea at NAUTH Neni from January 2016 through December 2020

\subsubsection{Exclusion criteria}

- Children aged more than five years who were diagnosed of diarrhoea in NAUTH Neni.

- Children aged less than five years who received care for diarrhoea at NAUTH Neni but not within the stipulated time range of this study (January 2016 through December 2020)

\subsection{Sampling technique}

Consecutive sampling technique was used.

\subsection{Sample size determination}

This will be calculated using the Cochran formula [15], which is given as;

$$
\mathrm{n}=\frac{Z^{2} p q}{d^{2}}
$$

Where $\mathrm{n}$ - minimum sample size

$\mathrm{Z}$-standard normal deviate $=1.96$

p -population proportion $=2.7 \%[14]$.

$q-(1-p)$

$\mathrm{d}-$ degree of precision $=0.05$

therefore, $\mathrm{n}=\frac{1.96^{2} \times 0.027 \times 0.973}{0.05^{2}}$

$\mathrm{n}=40.37$

thus, the minimum sample size will be 40 .

\subsection{Study instruments}

A pro forma was designed to record the patients' profile which included; age, sex, year and season of diagnosis.

\subsection{Data collection method}

With permission from the records department NAUTH Neni, records of children aged less than five years who were managed for diarrhoea within January $1^{\text {st }} 2016$ - December $31^{\text {st }} 2020$ was identified, studied and needed data extracted from them.

\subsection{Data Analysis}

All available data was analyzed using statistical packages for social sciences (SPSS). Variables analyzed include; age, (which is a continuous data) sex, season and year of diagnosis of disease (which are categorical data). A T-test was analyzed comparing significance in occurrence of diarrhoea with respect to sex.

\subsection{Ethical Considerations}

This research work was done with permission from Nnamdi Azikiwe Teaching Hospital Ethical Committee (NAUTHEC) with ethical approval number NAUTH/CS/66/VOL.14/VER.3/100/2021/092. The aim of the study was explained to the records department NAUTH Neni and their approval requested. Information obtained from case notes was only used for the purpose of this project and patient's identity was kept confidential. 


\section{Results}

A five-year retrospective study was carried out to determine the prevalence of diarrhoeal disease among under five (5) paediatric patients at Nnamdi Azikiwe university teaching hospital (NAUTH) Neni from 2016 - 2020. The result is as presented in the tables below: This study at NAUTH, Neni out of 897 under five paediatric patients that presented within the said period of study. The results are as presented in the tables and figures below:

\subsection{Prevalence of diarrhoeal diseases}

Table 1 Prevalence of diarrhoea diseases among under five (5) pediatric patients at Nnamdi Azikiwe University Teaching Hospital (NAUTH) Neni from 2016 - 2020

\begin{tabular}{|c|c|c|c|}
\hline Year & No of cases & Total no of paediatric patients & Prevalence (\%) \\
\hline 2016 & 40 & 195 & 20.51 \\
\hline 2017 & 19 & 185 & 10.27 \\
\hline 2018 & 14 & 157 & 8.92 \\
\hline 2019 & 20 & 192 & 10.42 \\
\hline 2020 & 35 & 168 & 20.83 \\
\hline
\end{tabular}

The result of the prevalence of diarrhoea disease within the period of study is as presented in table 1 below. Out of a total of 897 under-five (5) pediatric patients recorded within the period of study, 128 were a case of diarrhoeal disease giving a prevalence of $14.27 \%$.Table 1 below reveals that the highest prevalence of diarrhoeal disease was recorded in $2020(20.83 \%)$ followed closely by 2016 with a prevalence of $20.51 \%$. The least prevalence was recorded in 2018 $(8.92 \%)$.

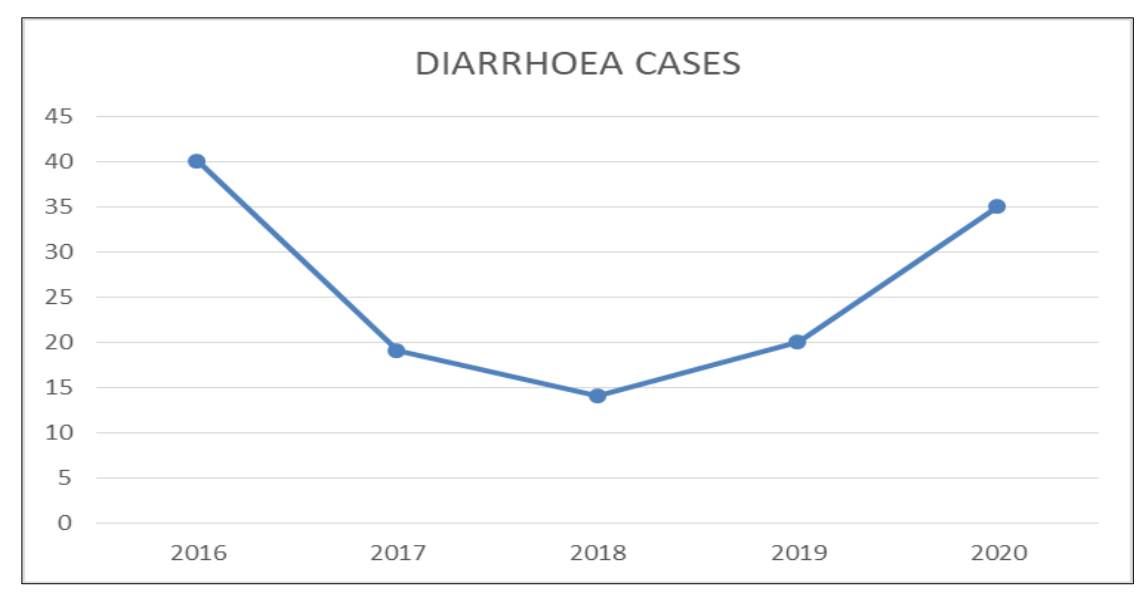

Figure 1 Trend Line Graph showing diarrhoea disease cases among under-five Pediatric Patients at NAUTH, Neni from 2016 to 2020

From fig 1 above it was observed that there was a sharp drop in diarrhea disease cases among under-five Pediatric Patients at NAUTH, Neni from 40 in 2016 to 19 in 2017. This further improved to 14 cases in 2018 but experienced a continuous rise to 20 cases in 2019 and 35 cases in 2020 (fig 1 above).

Table 2 summarizes the socio-demographic characteristics of the study sample. A total of 128 cases of diarrhea disease was recorded during the period of study with majority 62(48.4\%) within the age bracket of $0-11$ months followed by those within the age bracket of 12-23 month 32(25.0\%) with those within the ages 48-59months having the least cases $8(6.3 \%)$. Males were more affected $78(60.9 \%)$ than females; $50(39.1 \%)$. Higher number of cases was recorded in the dry season $96(75.0 \%)$ than the wet season with a total of $32(25.0 \%)$ cases. The highest number of cases was recorded in 2016; 40 (31.3\%) cases while in 2018 the least number of cases was recorded. 
Table 2 Socio demographic variables of under-five pediatric patients at Nnamdi Azikiwe University Teaching Hospital (NAUTH) Neni from $2016-202$

\begin{tabular}{|l|c|c|}
\hline Variable & Frequency & Percentage (\%) \\
\hline Age (months) & 62 & 48.4 \\
\hline $0-11$ & 32 & 25.0 \\
\hline $12-23$ & 16 & 12.5 \\
\hline $24-35$ & 10 & 7.8 \\
\hline $36-47$ & 8 & 6.3 \\
\hline $48-59$ & 50 & 39.1 \\
\hline Sex & 78 & 60.9 \\
\hline Female & \multicolumn{2}{|l|}{} \\
\hline Male & 40 & 31.3 \\
\hline Year under survey & 19 & 14.8 \\
\hline 2016 & 14 & 10.9 \\
\hline 2017 & 20 & 15.6 \\
\hline 2018 & 35 & 27.3 \\
\hline 2019 & 96 & 75.0 \\
\hline 2020 & 32 & 25.0 \\
\hline Season & \multicolumn{2}{|l|}{} \\
\hline Dry (November-March) & 96 & \\
\hline wet (April-October) & \multicolumn{2}{|l|}{} \\
\hline
\end{tabular}

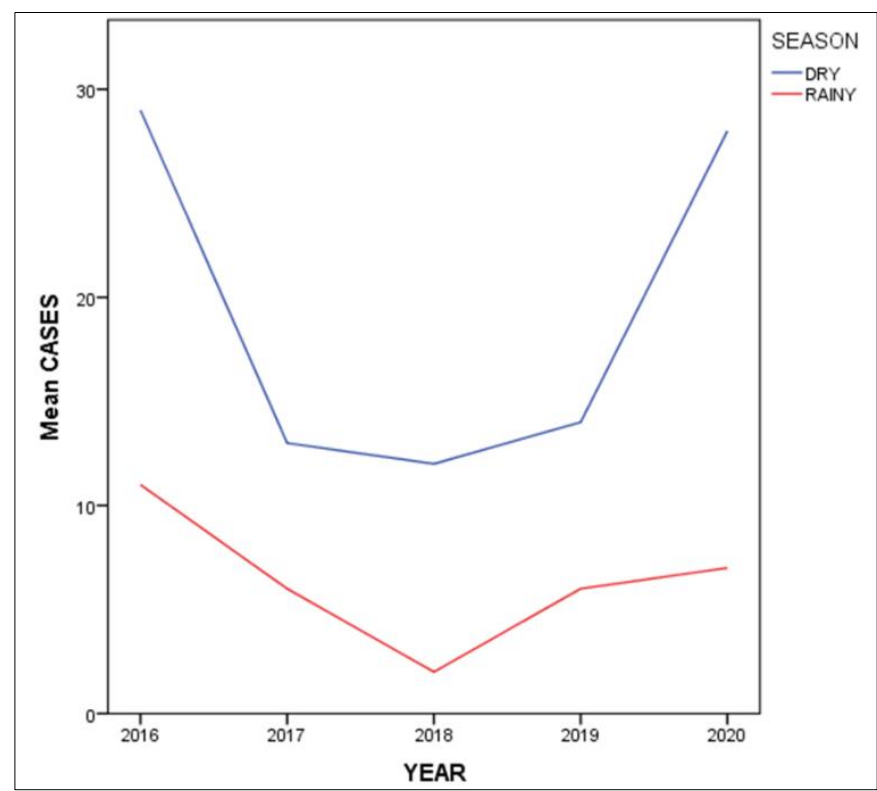

Figure 2 Mean cases of diarrhoea during the dry and wet seasons from 2016 - 2020

Figure 2 above shows the cases of diarrhea disease by season among under-five paediatric patients at NAUTH Neni within the period under review. Higher cases of diarrhoeal disease was recorded in the dry season throughout the period under review as shown in fig 2 above and both seasons show similar trend of decline from 2016 to 2018 but then rose from 2019 to 2020. 
Table 3 Independent t-test of cases of diarrhea between male and female

\begin{tabular}{|l|l|c|c|c|}
\hline \multicolumn{2}{|c|}{ Variable } & t & Df & P-VALUE \\
\hline \multirow{2}{*}{ SEX * CASES } & Equal variances assumed & -.624 & 126 & 0.534 \\
\cline { 2 - 5 } & Equal variances not assumed & -.614 & 99.431 & \\
\hline
\end{tabular}

Table 3 shows the independent T-test of cases between male and female under five who presented with diarrhoea. Pvalue $=0.534$ which is greater than 0.5 . Thus, there is no statistically significant difference between male and female occurrence of diarrhoea though there was a numerical difference in male (78) and female (50) with regards to this study.

Table 4 Independent T-Test of cases of diarrhea between dry and wet season

\begin{tabular}{|c|c|c|c|}
\hline Variable & T & df & P-value \\
\hline Diarrhoea cases*Season & 32.532 & 127 & 0.000 \\
\hline
\end{tabular}

Table 4 shows the T-test comparison of diarrhoea cases in dry and wet seasons. A P-value of 0.00 which is less than 0.5 implies that occurrence of diarrhoea is statistically more in dry season (96 cases recorded) than in the wet season (32 cases recorded).

\section{Discussion}

This study was carried out to determine the prevalence of diarrhoeal diseases among under-five paediatric patients at Nnamdi Azikiwe University Teaching Hospital (NAUTH) Neni, a 5-year review. The study revealed that out of a total of 897 under five paediatric patients that visited NAUTH Neni within the said period of the study, 128 diarrhoeal cases were recorded with a calculated prevalence of $14.27 \%$. This comes close in comparison to the prevalence of childhood diarrhoea in Nigeria; 18.8\% [2,7]. This is also in keeping with the prevalence in a work done at Dale District, Sidama Zone, Southern Ethiopia where a prevalence of $13.6 \%$ was obtained on diarrhoeal diseases in under five [17]. The highest number of cases was recorded in 2016; 40 cases (31.3\%) while in 2018 the least number of cases was recorded; 14(10.9).

With regards to the pattern/seasonal variation, of the 128 cases recorded, 96 cases (75\%) were recorded between the months of November through March (dry/harmattan season) while the remaining 32 cases (25\%) were recorded between the months of April through October (wet season). This finding is similar to that seen in the study done by Karen Levy ${ }^{[1,2]}$ and others on the seasonality of Rotavirus (the most common cause of diarrhoea in children aged $<5$ years old) in the tropics. In the study, it was discovered that diarrhoea-causing Rota virus responds to changes in climate in the tropics, with the highest number of cases found at the colder and drier times of the year. Furthermore, in a study done by Akinbami and Peterside [7], it was stated that in tropical countries, including Nigeria, viral diarrhoea tend to occur throughout the year with an increase during the drier colder months (harmattan/dry season), while bacterial diarrhoea tend to occur more during the warmer wet seasons. From my study also, occurrence of diarrhoea was both numerically and statistically more in dry season ( 96 cases recorded) than in the wet season (32 cases recorded).

Relationship of occurrence of diarrhoea with age in this study shows that of the total 128 cases recorded, 62 (48.4\%) were within the age 0-11 months followed by children within the age of $12-23$ months; $32(25 \%)$ and those within the age of 48-59 months having the least number of cases recorded; 8 (6.3\%). It is thus agreeable to state that diarrhoeal diseases have an inverse relationship with increasing age. This finding is similar to that of a study done in Kashmir, India by Siraj FA [13] and others on the prevalence of diarrhoeal diseases, its seasonal and age variation in under-fives. It is also in tandem with the findings of a study done in Ibadan, Nigeria by DesmennuAdeyimika T, Oluwasanu, JohnAkinola[15] et al in 2007. In the study, it showed that children aged between 7-18 months were found to experience higher occurrence of diarrhoea when compared to that of children aged more than 18 months.

In this study, of the 128 total cases of diarrhoeal cases recorded, 78 (60.9\%) were males and 50 (39.1\%) females. Though there was a numerical difference, it was discovered by T-test comparison that there are no statistically significant differences between male and female occurrence of diarrhoea. This mirrors the work of a study done at Jos University 
Teaching Hospital on Prevalence of diarrhoeal diseases in children < 5 years [14]. Here, of a total of 340 diarrhoea cases recorded in a 24 months' duration, 183 (54\%) were males and 157 (40\%) females. However, it was concluded that although there were more males affected, the risk of having diarrhoea was not significantly related to sex.

\section{Conclusion}

Results obtained from this study shows that the prevalence of diarrhoeal disease among under five paediatric patients at NAUTH Neni, form January 2016 through December 2020 is $14.27 \%$. It also shows that there is a significant seasonal influence on diarrhoeal disease in under-five paediatric patients.It can thus be concluded that diarrhoea occurs more in the dry season in this region than in the WET season. From the study, it is also obtainable to say that the general risk of diarrhoea decreases with increasing age in children and toddlers are the most at risk group of suffering the disease. With regards to sex factor, in this study as well as in some other studies cited in this work, males were affected more than females with a calculated ratio of female 1:1.6 male. Thus, it remains unwise to conclude without any attributable factor that the risk of diarrhoea is significantly higher in a particular sex.

\section{Recommendations}

My recommendations are in line with the levels of prevention as diarrhoeal disease among children is a highly preventable disease.

\section{Primordial}

- Provision of clean potable water for cooking and drinking, and educating the rural society on simple means of water purification like boiling.

- Ensure proper environmental sanitation with proper means of waste disposal and management. Refuse should be cited far away from water sources.

- Primary

- Educating the general public with the mothers and women of child bearing age of particular interest on the benefits and importance of exclusive breast feeding in preventing diarrhoeal diseases in children.

- The entire public should be sensitized on immediate and appropriate health seeking behavior.

- Secondary

- The government should ensure adequate staffing of the primary health centers and availability of Oral rehydration salt solution (ORS), as this is the primary and most effective treatment meted out to patients presenting early with diarrhoeal disease. Mothers should as well be counselled and taught how to constitute the ORS properly. They are also taught the proper constitution of homemade sugar salt solution in times of lack of ORS.

- Adequate treatment of diarrhoeal diseases to prevent development of life threatening complications like hypovolemic shock or severe dehydration, and in cases where severe dehydration has developed, adequate and proper fluid management ensued.

- Tertiary

- Proper management of the possible complications that may arise following diarrhoeadiseaseto prevent further life debilitating conditions like use of anticonvulsants in treatment and prevention of seizures.

- Good and adequate hydration in patients after correction of dehydration and shock.

\section{Study limitations}

- Missing and incomplete patients' records.

- The study factors in only patients who sort care at the hospital which is actually a tertiary institution and thus may not reflect a representative of the general population of under five children and the actual prevalence.

\section{Compliance with ethical standards}

\section{Disclosure of conflict of interest}

The authors declared that there is no conflict of interest. 


\section{References}

[1] Felix OA, Oliemen P. Acute diarrhoea diseases in childhood: Paediatric and child health in a tropical region. 2016; 927-928.

[2] The United Nations Children's Fund (UNICEF)/World Health Organization (WHO), 2009. Diarrhoea: Why children are still dying and what can be done. ISBN 978-92-806-4462-3 (UNICEF). ISBN 978-92-4-159841-5 (NLM classification: WS 312) (WHO).

[3] WHO. Diarrhoeal disease fact sheet. 2005.

[4] Centers for Disease control and prevention; Department of Health and Human Services for disease control and prevention in the united states; 2013. Diarrhoea: common illness, global killer.

[5] International Vaccine Access Center (IVAC): Pneumonia and diarrhoea Progress report: Johns Hopkins Bloomberg School of Public Health. 2014.

[6] UNICEF. Pneumonia and diarrhoea tackling the deadliest diseases for the world's poorest children. 2012.

[7] Nigeria demographic and health survey. Abuja, Nigeria: National population commission and ICF Macro. 2013.

[8] UNICEF. The state of the world's children in 2013: Child survival. New York, USA: Unicef. 2013.

[9] Ogunsanya TI, Rotimi VO, Adenuga A. A study of the etiological agents of childhood diarrhoea Lagos. J Med Microbiol. 1994; 40: 10 - 14.

[10] Pediatrics. 2008 Sep; 122(3): e541-9.

[11] WHO. 2007. Combating waterborne disease at the household level. Geneva, World Health Organization.

[12] Thiam S, Diène AN, Fuhrimann S, Winkler MS, Sy I, Ndione JA, et all. Prevalence of diarrhoea and risk factors among children under five years old in Mbour, Senegal: a cross-sectional study. Infect Dis Poverty. 2017 Jul 6; 6(1): 109.

[13] Levy K, Hubbard AE, Eisenberg JN. Seasonality of rotavirus disease in the tropics: a systematic review and metaanalysis. Int J Epidemiol. 2009 Dec; 38(6): 1487-96.

[14] Siraj FA, Farheen A, MuzaffarA,andMattoo GM. Prevalence of Diarrhoeal Disease, its Seasonal and Age Variation in under-fives in Kashmir, India.Int J Health Sci (Qassim). 2008 Jul; 2(2): 126-133.

[15] Yilgwan CS, Okolo SN. Prevalence of diarrhoeal disease and risk factors in Jos University Teaching Hospital, Nigeria. Ann Afr Med. 2012 Oct-Dec; 11(4): 217-21.

[16] DesmennuAdeyimika T, OluwasanuMojisola M, John Akinola, Yetunde O, OladunniOpeyemi, Adebowale S. Maternal Education and diarrhoea among children aged 0-24 months in Ibadan, Nigeria. African journal of Reproductive health. 2007; 21(3): 27.

[17] Brinkhoff T. Anaocha Local Government Area in Nigeria. [Online].

[18] Melese B, Paulos W, Astawesegn FH, Gelgelu TB. Prevalence of diarrheal diseases and associated factors among under-five children in Dale District, Sidama zone, Southern Ethiopia: a cross-sectional study. BMC Public Health. 2019 Sep 6; 19(1): 1235. 